\title{
FORMAÇÃO DE PROFESSORES PARA O ATENDIMENTO EDUCAÇONAL ESPECIALIZADO
}

\section{TRAINING OF TEACHERS FOR SPECIALIZED EDUCATIONAL CARE.}

\section{Ana Abadia dos Santos Mendonça}

Doutoranda em Educação. Universidade de Uberaba (UNIUBE). End. Res. Rua Espírito Santo, № 1096. Bairro Brasil. 38.400-660. Uberlândia MG.

E-mail: ana_abadia@yahoo.com.br.

CAPES.

\section{Resumo}

É uma investigação científica que discute a formação de professores para o Atendimento Educacional Especializado nas Salas de Recursos Multifuncionais das escolas regulares da educação básica. O artigo faz uma introdução tendo como foco as políticas públicas de educação especial e inclusiva. A Constituição Federal de 1988 e a Lei de Diretrizes e Bases da Educação Nacional - 9394/96 foram pano de fundo para mostrar que o AEE está previsto em duas das leis que tratam dessa modalidade educacional e de modo especial citam o Atendimento Educacional Especializado como coparticipante na escolarização das pessoas com deficiências na escola básica regular. O artigo tem como objetivos: identificar, discutir e propor soluções para a formação do professor de AEE para atuarem nas salas de recursos multifuncionais. É um estudo de caráter bibliográfico de cunho pedagógico voltado aos alunos com deficiências que estão dentro das escolas regulares da educação básica. Assim, considera o professor de AEE é multiprofissional, executa seu trabalho com todas as deficiências no contra turno e promove a aprendizagem de conteúdos que são pré-requisitos para a escolarização do aluno com deficiência na sala de aula regular.

Palavras-chave: Formação de Professores, Atendimento Educacional Especializado, Alunos com deficiências; Salas de Recursos Multifuncionais.

\section{ABSTRACT}

It is a scientific investigation that discusses the training of teachers for Specialized Educational Services in Multifunctional Resource Rooms in regular primary education schools. The article makes an introduction focusing on public policies for special and inclusive education. The Federal Constitution of 1988 and the Law of Guidelines and Bases for National Education - 9394/96 were the background to show that the AEE is provided for in two of the laws that deal with this educational modality and, in a special way, mention the Specialized Educational Service as a co-participant in the schooling of people with disabilities in regular primary school. The article has as objectives: to identify, discuss and propose solutions for the formation of the AEE teacher to work in multifunctional resource rooms. It is a 
bibliographical study of a pedagogical nature aimed at students with disabilities who are in regular basic education schools. Thus, it considers the AEE teacher to be multidisciplinary, performs their work with all the deficiencies in the counter shift and promotes the learning of contents that are prerequisites for the schooling of students with disabilities in the regular classroom.

Keywords: Teacher Education, Specialized Educational Service, Students with disabilities, Multifunctional Resource Rooms.

\section{INTRODUÇÃO}

A educação inclusiva é uma modalidade educacional prevista na Constituição Federal Brasileira de 1988 e na Lei de Diretrizes e Bases da Educação Nacional (LDB) 9394 de 1996. Ela deve ser realizada nas escolas regulares da educação básica independente de serem públicas, privadas e/ou filantrópicas.

A Constituição Federal de 05 de outubro de 1988, em seu Art. 208, estabelece a integração escolar como preceito constitucional, preconizando o atendimento aos indivíduos que apresentam deficiência, preferencialmente na rede regular de ensino. Podemos dizer que ficou assegurado pela Constituição Brasileira (1988) o direito de todos à educação, garantindo-se, assim a matricula de crianças com deficiências na escola regular de ensino e o atendimento educacional especializado de pessoas que apresentam necessidades educacionais especiais.

Segundo Bueno (1994), é mínimo o acesso à escola de pessoas que apresentam deficiência intelectual, com o agravante de servir mais a legitimação da marginalidade social do que à ampliação das oportunidades educacionais para essa população.

Ainda no Art. 206, inciso I, estabelece que o ensino seja ministrado com base no princípio da igualdade de condições para o acesso e permanência na escola. Mais adiante no Art. 208, inciso III, assegura a integração escolar como preceito constitucional, preconizando o atendimento escolarizado e o Atendimento Educacional Especializado (AEE) aos indivíduos que apresentam deficiência, preferencialmente na rede regular de ensino.

A escola regular ainda busca alternativas para conduzir a inclusão de crianças deficientes. Estão desinformadas, mal estruturadas, não possuem espaço físico adequado para o atendimento extra turno no AEE e os professores 
ainda resistem a esta modalidade de ensino.

É interessante considerar que os serviços especializados e o atendimento das necessidades específicas dos alunos garantidos pela lei estão muito longe de ser alcançados. "Identificamos, no interior da escola, a carência de recursos pedagógicos e a fragilidade da formação dos professores para lidar com essa clientela" (MANTOAN, 1997, p.77).

A LDB 9394/96 vigente até os dias atuais trata no Art. $2^{\circ}$ e $3^{\circ}$ que a educação tem por "finalidade o pleno desenvolvimento do educando e seu preparo para a cidadania" e que deverá ser ministrado entre outros incisos, com "igualdade de condições para o acesso e permanência na escola, com garantia de padrão de qualidade".

No seu Art. 4ํㅜ o Estado garante que é seu dever garantir educação escolar pública e obrigatória para todos os alunos do ensino fundamental, "inclusive para os que a ele não tiveram acesso na idade própria", e no inciso III, afirma que "atendimento educacional especializado gratuito aos educandos com necessidades especiais, preferencialmente na rede regular de ensino" (BRASIL, 1996, s/p).

Para fins do serviço de AEE, os pontos da Lei são:

$\S 1$ 1 Haverá, quando necessário, serviços de apoio especializado, na escola regular, para atender às peculiaridades da clientela de educação especial.

$\S 2^{\circ} \mathrm{O}$ atendimento educacional será feito em classes, escolas ou serviços especializados, sempre que, em função das condições específicas dos alunos, não for possível a sua integração nas classes comuns de ensino regular (LDB 9394/96).

Ainda neste capítulo aparece o Art. 59, que menciona que os sistemas de ensino deverão assegurarão aos "educandos com necessidades especiais":

III - professores com especialização adequada em nível médio ou superior, para atendimento especializado, bem como professores do ensino regular capacitados para a integração desses educandos nas classes comuns (LDB 9394/96).

A prática educativa das escolas regulares mostra a dificuldade dos profissionais em educação em trabalhar na escola regular inclusiva com as diversas deficiências.

Mantoan (2006) afirma que "o mote da inclusão, ao contrário, é não deixar 
ninguém no exterior do ensino regular, desde o começo da vida escolar". Assim fica claro que as crianças com deficiências devem frequentar a escola independente de sua idade. A escola deve se preparar para recebê-las em qualquer nível escolar, desde a educação infantil e até nos berçários, onde estes já começarão a se integrar com outras crianças representativas da normalidade, favorecendo o amadurecimento e os diversos aprendizados da vida cotidiana, como cuidar da higiene, participação nas brincadeiras diversas, alimentar sozinho, etc.

A escolarização de alunos com deficiência, transtornos globais do desenvolvimento e altas habilidades/superdotação tem desafiado os espaços escolares a construírem novas/outras lógicas de ensino. Diante disso, a formação docente tem se configurado como uma possibilidade de pensar as demandas escolares e os processos de escolarização dos sujeitos que também são públicoalvo da educação especial.

Assim, esta pesquisa tem como objetivos, identificar, discutir e propor soluções para a formação do professor de AEE para atuarem nas salas de recursos multifuncionais.

Como metodologia, o estudo teve com suporte o caráter bibliográfico de cunho pedagógico voltado aos alunos com deficiências que estão dentro das escolas regulares da educação básica.

\section{ATENDIMENTO EDUCACIONAL ESPECIALIZADO (AEE)}

Durante o processo de criação da educação inclusiva, as legislações pertinentes também tratam do AEE. Ele é um serviço da educação especial que “identifica, elabora, e organiza recursos pedagógicos e de acessibilidade, que eliminem as barreiras para a plena participação dos alunos, considerando suas necessidades específicas" (SEESP/MEC, 2008).

O especialista do AEE faz a ponte entre o aluno e o professor da sala de aula comum, permitindo uma troca de experiência que contribua nesse processo educacional e em todo o contexto escolar, bem como a inserção na sociedade.

A lei diz que a oferta de educação especial deve ocorrer preferencialmente na rede regular de ensino. Isso quer dizer que o ideal é que a escola comum tenha uma sala de recursos multifuncionais e uma equipe 
especialista para oferecer o atendimento educacional especializado dentro da escola. (BRASIL, 2011)

Segundo Mantoan (2003, p.23) "o 'preferencialmente' refere-se a 'atendimento educacional especializado', ou seja: o que é necessariamente diferente no ensino para melhor atender às especificidades dos alunos com deficiência, abrangendo principalmente instrumentos necessários à eliminação das barreiras que as pessoas com deficiência naturalmente têm para relacionarse com o ambiente externo, como, por exemplo: ensino da Língua Brasileira de Sinais (Libras), do código braile, uso de recursos de informática, e outras ferramentas e linguagens que precisam estar disponíveis nas escolas ditas regulares".

De acordo com as Diretrizes Operacionais da Educação Especial para o Atendimento Educacional Especializado na Educação Básica (2008) coloca:

O atendimento educacional especializado - AEE tem como função identificar, elaborar e organizar recursos pedagógicos e de acessibilidade que eliminem as barreiras para a plena participação dos alunos, considerando suas necessidades específicas.

Esse atendimento complementa e/ou suplementa a formação dos alunos com vistas à autonomia e independência na escola e fora dela (BRASIL, 2008, p. 1).

Ainda considera-se:

[...] serviços e recursos da educação especial àqueles que asseguram condições de acesso ao currículo por meio da promoção da acessibilidade aos materiais didáticos, aos espaços e equipamentos, aos sistemas de comunicação e informação e ao conjunto das atividades escolares (BRASIL, 2008, p. 1).

O AEE é realizado na Sala de Recursos Multifuncionais (SRM) da mesma escola onde o aluno com deficiência estuda, ou em outra unidade escolar que tenha o espaço adequado e o profissional capacitado. É importante destacar que esse atendimento é realizado no turno inverso do que acontece a escolarização.

O púbico alvo do AEE:

Alunos com deficiência: aqueles que têm impedimentos de longo prazo de natureza física, intelectual, mental ou sensorial, os quais, em interação com diversas barreiras, podem obstruir sua participação plena e efetiva na sociedade em igualdade de condições com as demais pessoas (BRASIL, 2008, p. 2). 
Também devem contar com o mesmo serviço:

Alunos com transtornos globais do desenvolvimento: aqueles que apresentam um quadro de alterações no desenvolvimento neuropsicomotor, comprometimento nas relações sociais, na comunicação ou estereotipias motoras. Incluem-se nessa definição alunos com autismo clássico, síndrome de Asperger, síndrome de Rett, transtorno desintegrativo da infância (psicoses) e transtornos invasivos sem outra especificação (BRASIL, 2008, p. 2).

Ainda devem ser atendidos:

Alunos com altas habilidades/superdotação: aqueles que apresentam um potencial elevado e grande envolvimento com as áreas do conhecimento humano, isoladas ou combinadas: intelectual, acadêmica, liderança, psicomotora, artes e criatividade (BRASIL, 2008, p. 2).

A oferta do AEE deve constar no Projeto Político Pedagógico (PPP) da escola regular de educação básica que oferece esse serviço. A sua organização deve prever:

a. Sala de recursos multifuncional: espaço físico, mobiliários, materiais didáticos, recursos pedagógicos e de acessibilidade e equipamentos específicos;

b. Matrícula do aluno no AEE: condicionada à matrícula no ensino regular da própria escola ou de outra escola;

c. Plano do AEE: identificação das necessidades educacionais específicas dos alunos, definição dos recursos necessários e das atividades a serem desenvolvidas; cronograma de atendimento dos alunos;

d. Professor para o exercício da docência do AEE;

e. Profissionais da educação: tradutor e intérprete de Língua Brasileira de Sinais, guia-intérprete e outros que atuam no apoio às atividades de alimentação, higiene e locomoção.

f. Articulação entre professores do AEE e os do ensino comum. g. Redes de apoio: no âmbito da atuação intersetorial, da formação docente, do acesso a recursos, serviços e equipamentos, entre outros que contribuam para a realização do AEE (BRAIL, 2008, p. $3)$.

Para que o AEE se efetive, as escolas que oferecem este serviço devem ser dotadas de Salas de Recursos Multifuncionais. As SRMs são espaços na escola regular, em que o professor de educação especial, realiza o AEE para os alunos público alvo da educação especial, por meio do desenvolvimento de estratégias de aprendizagem, com recursos específicos disponíveis nestas salas 
(BRASIL, 2012).

Um estudo realizado por Baptista (2011) mostra que durante muito tempo o investimento para o AEE era feito em classes e escolas especiais. Dessa forma, a existência desses ambientes esteve reduzida, principalmente, ao contexto das instituições especiais. Isso explica o fato de pouco se discutir na literatura o ambiente das SRMs, que vem sendo implementada nas escolas públicas e reflete a iniciativa de uma prática educacional inclusiva.

Sartoretto e Bersch (2014) revelam que nas SRMs existe uma variedade de materiais e equipamentos específicos, recursos de acessibilidade, materiais didáticos, pedagógicos e mobiliários adequados para o atendimento de alunos com necessidades educacionais no contraturno.

\title{
3 FORMAÇÃO DOS PROFESSORES DE AEE
}

O crescente número de matrículas de crianças com deficiência no ensino regular impacta diretamente a organização escolar. Educadores, gestores e demais profissionais da educação, em geral, têm pouco embasamento para desenvolver práticas que possam ser, de fato, inclusivas.

A Política Nacional de Educação Especial na perspectiva da Educação Inclusiva (PNEEPEI) destaca que, além do exercício da docência, os professores do AEE também tenham conhecimentos específicos da área:

\begin{abstract}
$O$ atendimento educacional especializado é realizado mediante a atuação de profissionais com conhecimentos específicos no ensino da Língua Brasileira de Sinais, da Língua Portuguesa na modalidade escrita como segunda língua, do sistema Braille, do Soroban, da orientação e mobilidade, das atividades de vida autônoma, da comunicação alternativa, do desenvolvimento dos processos mentais superiores, dos programas de enriquecimento curricular, da adequação e produção de materiais didáticos e pedagógicos, da utilização de recursos ópticos e não ópticos, da tecnologia assistiva e outros (BRASIL, 2008, p.11).
\end{abstract}

Portanto, além de um professor, o AEE, requer um especialista de acordo com o que prevê a Política: um especialista em Educação Especial. Glat et al (2011, p.32) destaca que um dos maiores entraves à inclusão ainda está na precariedade da formação inicial e continuada dos professores. A ação do professor especialista precisa ser baseada em conhecimentos específicos sobre 
como ensinar os alunos e sobre quais as intervenções adequadas. As atividades desenvolvidas no AEE se diferem das atividades desenvolvidas na sala de aula comum.

A primeira estruturação que ocorre nessa formação parte da compreensão de que o professor do AEE não é um especialista em uma dada deficiência. Seu objetivo é conhecer o aluno, identificar suas possibilidades e necessidades, traçar um plano de AEE para que possa organizar os serviços, as estratégias e os recursos de acessibilidade. A formação, então, não tem por base o estudo de uma única deficiência. Ela deve estabelecer uma interlocução entre os conhecimentos que são próprios do AEE com as situações reais do cotidiano escolar.

Para atuar no AEE, os professores devem ter formação específica para este exercício, que atenda aos objetivos da educação especial na perspectiva da educação inclusiva. Nos cursos de formação continuada, de aperfeiçoamento ou de especialização, indicados para essa formação, os professores atualizarão e ampliarão seus conhecimentos em conteúdos específicos do AEE, para melhor atender a seus alunos.

Entre as responsabilidades do professor, constata-se dois espaços de atuação, com a existência da SRM tipo 1 e da SRM tipo 2. Cada espaço dispõe de materiais diferenciados, sendo que a segunda se destina, também, ao trabalho com alunos da área visual e a primeira o trabalho com alunos das demais áreas que compõe o público alvo da educação especial.

São atribuições do professor do atendimento educacional especializado:

a. Identificar, elaborar, produzir e organizar serviços, recursos pedagógicos, de acessibilidade e estratégias considerando as necessidades específicas dos alunos público-alvo da educação especial;

b. Elaborar e executar plano de atendimento educacional especializado, avaliando a funcionalidade e a aplicabilidade dos recursos pedagógicos e de acessibilidade;

c. Organizar o tipo e o número de atendimentos aos alunos na sala de recursos multifuncional;

d. Acompanhar a funcionalidade e a aplicabilidade dos recursos pedagógicos e de acessibilidade na sala de aula comum do ensino regular, bem como em outros ambientes da escola;

e. Estabelecer parcerias com as áreas intersetoriais na elaboração de estratégias e na disponibilização de recursos de acessibilidade;

f. Orientar professores e famílias sobre os recursos pedagógicos e de acessibilidade utilizados pelo aluno;

g. Ensinar e usar recursos de Tecnologia Assistiva, tais como: as 
tecnologias da informação e comunicação, a comunicação alternativa e aumentativa, a informática acessível, o soroban, os recursos ópticos e não ópticos, os softwares específicos, os códigos e linguagens, as atividades de orientação e mobilidade entre outros; de forma a ampliar habilidades funcionais dos alunos, promovendo autonomia, atividade e participação.

h. Estabelecer articulação com os professores da sala de aula comum, visando a disponibilização dos serviços, dos recursos pedagógicos e de acessibilidade e das estratégias que promovem a participação dos alunos nas atividades escolares.

i. Promover atividades e espaços de participação da família e a interface com os serviços setoriais da saúde, da assistência social, entre outros (BRASIL, 2012, p. 8-9).

Ao analisar as atribuições do professor, compreende que a multifuncionalidade é expressa também nas ações desse profissional e sugere a conceituação de "professor multifuncional" (VAZ, 2013, p. 183).

Mendes (2006) considera que quando o professor de AEE e o professor da sala regular dividem o planejamento, a avaliação e até mesmo instruções dadas aos alunos, eles estão estabelecendo uma parceria profissional em prol do processo de ensino aprendizagem dos alunos. Um dos modelos com destaque atualmente na literatura para esse trabalho é o ensino colaborativo ou co-ensino (MENDES; VILARONGA; ZERBATO, 2014).

A Resolução n. 4 de 2009 estabelece que "para atuação no AEE, o professor deve ter formação inicial que o habilite para o exercício da docência e formação específica para a educação especial" (BRASIL, 2009a, p. 3).

De acordo com Michels:

[...] a centralidade das ações dos professores do atendimento educacional especializado (AEE) permanece nas técnicas e nos recursos especializados [...]. Mesmo aquelas ações que dizem respeito à articulação com a classe comum não estão atreladas à discussão pedagógica, e sim a utilização de recursos específicos. (MICHELS, 2011, p. 226).

Compreende-se, assim, que, a partir de 2008, o AEE adquiriu definições mais precisas que permitem a implementação em âmbito nacional. À medida que é reforçado o indicativo de que a escolarização das pessoas com deficiência deve se dar no ensino comum da escola regular, ascende a necessidade de apoio de um atendimento diferenciado que dê suporte a professores e alunos, uma vez que não basta a inserção desse alunado na sala comum, fazem-se necessárias 
condições e suportes adequados.

O professor do AEE tem como função de implementar ou suplementar para 0 aluno 0 uso desses recursos e estratégias necessários para 0 desenvolvimento de ensino-aprendizagem dos mesmos. Além de acompanhar a funcionalidade e usabilidade desses recursos (BRASIL, 2011).

Outra atribuição do professor de AEE, importante e contemplada no documento, refere-se à realização o atendimento de forma articulada com os professores da sala regular. No entanto, percebe-se que há um déficit neste ponto junto ao atendimento dos alunos público-alvo da educação especial, uma vez que o AEE fica centralizado nas SRMs apresentando modelo único de atendimento.

\section{CONSIDERAÇÕES FINAIS}

A formação de professores para o Atendimento Educacional Especializado é um tema bastante significativo, pois estes profissionais trabalham para assessorar o professor da sala regular nos conteúdos por ele ministrados. É um trabalho que precisa voltar sua atenção às particularidades de cada indivíduo com deficiência que chegue à Sala de Recursos Multifuncionais.

Sua formação está embasada em princípios que tratam da educação inclusiva e é para essa educação que o AEE foi instituído por legislação pertinente. Também precisa estar em constante estudo e a formação continuada é também uma exigência legal.

Formação teve como objetivo fazer educadores superarem a ideia de que existe uma "receita pronta" para incluir estudantes com deficiência.

A multifuncionalidade do professor de AEE é uma característica clara da atuação deste profissional na educação regular. O atendimento acontece ao turno inverso da escolarização dos alunos e precisa constar no PPP da escola, além de ter um espaço adequado especialmente preparado para esse atendimento, que são as Salas de Recursos Multifuncionais.

É importante salientar também que o professor de AEE não trabalha sozinho, ele deve estar em constante contato com o professor da sala regular para trocar informações a respeito do aluno e sua progressão na escolarização. A elaboração de um Plano de Desenvolvimento Individual do Aluno (PDI) permite que o planejamento das atividades da SEM tenha uma funcionalidade melhor. 
A formação do professor de AEE não tem por base o estudo de uma única deficiência. Sua atuação é abrangente, promovendo o atendimento a todos os alunos com deficiências físicas, motoras, cognitivas, sensoriais, transtornos globais do desenvolvimento e altas habilidades/superdotação. 


\section{REFERÊNCIAS}

BAPTISTA, C.R. Ação pedagógica e educação especial: a sala de recursos como prioridade na oferta de serviços especializados. Revista Brasileira de Educação

Especial, Marília, v. 17, n. spe1, Aug., p.59-76, 2011.

BRASIL. Documento Orientador Programa de Implantação de Salas de Recursos Multifuncionais. Brasília: MEC, SECADI, Diretoria de Políticas de Educação Especial, 2012.

BRASIL. Presidência da República. Decreto no 7.611, de 17 de novembro de 2011. Dispõe sobre a educação especial, 0 atendimento educacional especializado e dá outras providências. Brasília, 2011.

BRASIL. Resolução n. 04, de 02 de outubro de 2009. Institui as Diretrizes Operacionais para o Atendimento Educacional Especializado na Educação Básica - Modalidade Educação Especial. Ministério da Educação, Conselho Nacional de Educação, 2009a.

BRASIL. Política Nacional de Educação Especial na perspectiva da Educação Inclusiva. Ministério da Educação. Secretaria de Educação Especial. Brasília: MEC, 2008.

BRASIL. Ministério da Educação e Cultura. Lei no 9394, de 23 de dezembro de 1996. Lei que fixa as Diretrizes e Bases da Educação Nacional Brasileira. Brasília: 1996.

BRASIL. Constituição da República Federativa do Brasil de 1988. Brasília. 1988. Disponível em:

http://www.planalto.gov.br/ccivil_03/constituicao/constituicao.htm. Acesso em 21/07/2012.

BUENO, José Geraldo Silveira. Educação especial brasileira: integração/segregação do aluno diferente. São Paulo: EDUC, 1994.

GLAT, R.; PLETSCH, M. D. Inclusão escolar de alunos com necessidades educacionais especiais. Rio de Janeiro: EdUERJ, 2011, 162p. 
MANTOAN, Maria Teresa Égler. Inclusão escolar: o que é? Por quê? Como fazer? São Paulo: Moderna, 2006, 64p.

MANTOAN, Maria Teresa Égler. Ser ou estar, eis a questão: explicando o déficit intelectual. Rio de Janeiro: WVA, 1997.

MENDES, E. G. Colaboração entre ensino regular e especial: o caminho do desenvolvimento pessoal para a inclusão escolar. In: MANZINI, E.J. (org.)

Inclusão e acessibilidade. Marília: ABPEE, 2006, p. 29-41.

MENDES, E.G.; VILARONGA, C.A.R.; ZERBATO, A.P. Eunindo esforços entre educação comum e especial. 1. Ed. São Carlos-SP: EDUFSCar, 2014.

MICHELS, M. H. O que há de novo na formação de professores para a Educação Especial? Revista Educação Especial, Santa Maria, v. 24, n. 40, p. 219-232, maio/ago. 2011.

SARTORETTO, M. L.; BERSCH, R. Assistiva: tecnologia e educação.

Atendimento Educacional Especializado AEE. 2014. Disponível em <http://www.assistiva.com.br/aee.html>. Acesso em 20 mar. 2015.

VAZ, K. O Professor de Educação Especial nas Políticas de Perspectiva Inclusiva no Brasil: concepções em disputa. Dissertação de Mestrado. UFSC, 2013 